\title{
Bergson's Theory of Intellect and Reality-II
}

\author{
Is Our Intellect Limited in Its Powers?
}

\author{
By Norman J. Symons
}

\section{Concluded from Scientific American Supplement No. 2136, Page 371, December 9, 1916}

IT is here, however, that Bergson introduces his para-
dox. Granting, he says, that intellect handles novelty dox. Grant new situation as a combination of old familiar elements It is this which we deny. The chemist may represent novelty and change simply as a rearrangement of old atoms. But this method of dealing with novelty is not typical of our intellect as a whole. The theory in short that intellect, throughout its operations, understands a new situation only by first resolving it into a combination of old elements represents an impossibility in practice and also a poor logical theory. We bility in practice and also a
will take these points in order.

In every department of knowledge education consists above all in grasping certain universal principles and then learning to apply them to all sorts of varied situations. No one has shown this more clearly than Plato in a little dialogue called $I \bullet n$. Whereas Ion says that he is a supreme critic of Homer but cannot interpret any other branch of literature, Plato points out that if his skill rested upon intellectual principles he should be able to apply it not only to Homer but also to other writers. It is the same in all other spheres. The future general learns certain general principles of strategy. His success in the field will depend upon his ability to apply these to ever fresh situations. Intellectuality consists, in short, in just this ability to apply general principles to varied and different situations. But does this imply that if a principle has been applied to one this imply that if a principle has been applied to one
situation, the only possibility of applying it to different situations consists in analyzing all these into the same elements which formed the first, just as you may find the same bricks in the successive toy buildings which a child may erect? The answer is plain. Such an analysis would often be impossible in practice. The literary critic and the general interpret respective'y literary critic and the general interpret respective'y
all sorts of pieces of literature and strategical situations. And they do it by extending respectively the same principles to ever fresh circumstances. But the critic certainly never tries in interpreting fresh authors to reduce their works to a mere regrouping of the elements found in a first author; nor does the general have to represent a new strategical situation as a redistribution of the old elements occurring in a former situation, before he can understand it. The man, indeed, who could not apply a general principle to a fresh case without this laborious analysis would not be inteligent; he would be a rule-of-thumb kind of individua If he were a general the day would have been lost before he began to get under way.

But if this ideal of explanation is impracticable, it is also false in theory. Intellectuality consists, it was said, in the ability to apply a single principle to a number of diverse situations. To do this, beneath the detailed differences of these situations, one must see som element of sameness. Logicians are fond of pointin to the aspect of thought which sees the one in the many, sameness in difference. But this ability to see a single principle involved in all sorts of different applications does not mean, as Bergson implies, that by analysis and artificial manipulation we must represen all the different situations as made up of the same o similar elements. To take this view is to misunderstand the whole nature of intellect; it is to lose sight of the fact that the unity of every concept or principle consists in its ability to unify a real manifold. If before we can extend a single principle to different situations, we must somehow get rid of all their differences, the cardinal function of thought will be destroyed. There will be no longer any differences left in whic to see sameness.

Bergson's other point is that if intellect cannot understand real novelty still less can it produce it. It can only put old elements in a new order. It cannot, there new wholes only by creating new parts. This distinction also appears false; for intellect creates in just the same sense as life. The novelist who creates a work of fiction owes much to observation and experience. But even so, his finished work cannot be resolved into a mere regrouping of old empirical elements. His imagination creates new situations; and new characters which are not due to a mere fusion of different elements - oueens ouarterly. selected from actual personalities. For genius is cre-
ative; and it is also the highest form of intellect. In artistic production reason may be suffused with feelin But the fact that the greatest works of art are the most rational shows that reason is the spring of the artist's activity. To be creative one need not fall back upon the irrational or amorphous.

But eren in its more strictly logical operations intelect may be shown to be creative. As we get to know more about objects or situations their meaning expands for us continually. The most noteworthy in stance of this is in inference. The conclusion grows out of the premises and it is itself in relation to the something new as was the case with Darwin's famou conclusion which grew out of years of studied observation. Now Bergson maintains that all our intellect can do in the way of producing novelty is to rearrang old pre-existent elements. But if we attend to the actual psychology of inference, is it not absurd to say that inference itself consists in associating a pre-existent conclusion with the premises? Nothing of the sort. There is nothing but an indivisible process of expansion whereby the conclusion, occurring for the first time within consciousness, grows out of the premise Does not intellect, therefore, in the act of inference come very near to life itself, which, as Bergson says, create new wholes only by creating also the parts into which they may be analyzed?

In these few remarks we have tried to show, a against Bergson, that intellect is creative like life an can also understand real novelty such as life produces
The other half of Bergson's theory of knowledge may also be shown to be inadequate. When intellect fails us, we are told, we should turn to instinct or intuition to learn the secret of life's operation. Upon this point great emphasis is laid. In at least three different passages of his work, "Creative Evolution," Bergson maintains that instinct is molded on the very form of life and if questioned would give up life's secret. The biologist more especially is counseled to lay aside intellect and fall back upon immediate intuition. As long, says Bergson, as we study life with that intellect which has been designed to grapple with matter, so long shall we tend to reduce life to a dead mechanism, letting its meaning slip between our fingers. To understand life we should install ourselves right within its flow rather than study it from without; and to do this we must renounce intellect and take our stand upon that divining sympathy which is expressed on its cognitive side in what we call instinct or intuition.

Upon this semi-mystical ideal of the interpretation of life Bergson has much to say. But if we are willing to descend from the exalted level upon which he often moves and probe more cautiously beneath the surface we shall see that it is not sufficient to hail instinct triumphantly as the key to life's meaning. Even an advocate of intuition, such as Bergson, may rightly be called upon to show in some detail why, life and intuition both being what they are, the latter is peculiarly adapted to understand the former. But it is in
this detailed exposition that he appears to be lacking. this detailed exposition that he appears to be lacking.
It would be instructive to know, for instance, why, It would be instructive to know, for instance, why,
life being, in Bergson's opinion, characterized by radical contingency, inpredictability and the production of real novelty, intuition may be supposed to supply the key to its interpretation which intellect is said to lack. In the absence of any such explanation it may be shown that instinct or intuition is fundamentally unititted to grasp life's essential nature. A comparison will make this clear.

It is the essentially mobile character of life upon which Bergson always insists. "Life in general," he says, "is mobility itself." It is a process constantly welling over upon itself, renewing itself endlessly, always progressive; in short, the very antithesis of the mechanical and stereotyped. Is it not, therefore, strange that he proposes to find in instinct the clue to its interpretation? For while life is opposed to mechanism, instinct, when passing into action, comes so close to automatism that it has been even resolve into compound reflex action. While life again is progressive, societies based upon instinct appear to stand still, incapable of further development. Such is admitted by Bergson to be the case with those admirably ordered but stereotyped societies into which bees or ants form themselves. How, then, can one hope to fathom life, the mobile and progressive, by an appeal to instinct, the immobile and stereotyped? Might it not be said, as against Bergson, who contends that instinct is molded on the very form of life, that where life has taken on the form of instinct it has also taken on something of the nature of a mechanism?

If instinct as a whole thus appears opposed to life the logical character of the intuitive consciousness which guides instinctive action makes it unfitte to grasp the essential movement of life. For intuition cannot be generalized. The particular intuition which tells the organism how to behave in one situation will not tell it how to react in another and different situation. The same intuition, as Bergson notes, will not extend to a number of different objects. It applies only to one object or situation and often only to a restricted aspect of that. It is far otherwise with the principles which intellect employs. For intellectual principles are universal, one and the same principle being capable of being extended to a variety of different circumstances. This contrast between intuition and intellect brings out at once the logical defects of the former. If intellect working with one and the same concept or principle can interpret a variety of situations, it is because it is capable of seeing an element of sameness amid all the different situations. Conversely, if intuition is forever limited in its application to a single object or situation it is because the consciousness which works with intuition is radically incapable of seeing sameness in different situations. Dealing wholly with the specific and particular, it never attains to a grasp of the universal.

To make this admission is surely to put an end to the contention that in intuition we have an instrument which will reveal to us life's secret. For is not life, as we follow the process of its development in the genealogical tree of evolutionary descent, the very incarnation of the universe? Life, indeed, is the everlasting realization of the ideal of the one in the many. Throwing itself into endless species and individuals, it appears as their many different lives. That is one side of the matter, the aspect of difference and plurality. But there is also the aspect of unity and sameness. If that original vital impetus which first invaded the domain of inert matter has subsequently distributed the force of its impulsion along many and diverse paths so that the history of evolution is symbolize by a branching tree rather than by a chain, it is still one and the same life-force which is always at work. Everywhere we are struck by the infinite diversity of the forms which life has assumed, everywhere by the fact that all individual lives are but modes of the one over-individual universal life. Charged from the outset, as Bergson affirms, with the infinity of the diverse psychical potentialities of the species and individuals which were yet to be, life realized all its latent possibilities by branching in many different directions without sacrificing the unity of its original concentrated form. And if this method of development is essential, if it is the essence of life to develop like a sheaf as Bergson assures us, will it not also be true from a logical standpoint that life's process is the progressive realization of the one through the medium of the many? Life will be the supreme instance of that highest form of the universal which we call by the name of "concrete identity." Such being the logical character of life's development, in intuition which never grasps the universal, the one in the many, we shall never find the key to that process of life which; Bergson assures us, is life itself

From this point we may return once again to intellect. Would it not seem that it is intellect and not intuition which is molded on the very form of life? If life develops essentially as a one-in-many, does int intellect which expands itself in experience into a tho: sand different concepts, while still remaining self-ider, tical, do the same? And is not each of those principles into which our intellect progressively distills its being an illustration of life's nature; for each is a unity which embraces a real manifold even as life itself does. ln intellect indeed we seem to have a prolongation in clear consciousness of the sub-conscious logic of life 
essential process. Like life which, Bergson shows us, produces the same organs by different means, our intellect is marked by its ability to devise, upon occasion, fresh means to encompass the same ends. And if those infinitely subtle adaptations which the history of evolution exhibits cannot be explained mechanically but are due to a peculiar psychic force called life, that force seems in all respects nearer to intelligence than to instinct. We may grant that the intelligence which is life moves for the most part in the realm of the subconscious, that it does not in the lower reaches of evolution understand its own process. But in so far as it has explicitly evolved in man a self-conscious intellect it has also evolved a key to the interpretation of itself at large. If evolution has culminated in the intellect of man and if life is the mainspring of evolution, the whole history of organic development appears as a prolonged effort of life to supply a key to its own

\section{Nitrogen Oxides From Ammonia for the Lead Chamber Process*}

IT Is rather remarkable that some details of processes for the oxidation of nitrogen, worked out in Germany, have been published since the beginning of the war. When the war broke out all the saltpeter available in Germany was requisitioned for the use of explosive works, which, of course, want nitric acid. But nitric acid is indispensable as well for the manufacture of sulphuric acid on the old lead chamber method, which was still the most extensively used method in Germany. Deprived of one of their raw materials, saltpeter, those works would have had to shut down unless they could make nitric acid without using saltpeter. Two other ways of making nitric acid or nitrogen oxides had been open for some time. The one, about which much has been written, is the oxidation of atmospheric nitrogen with the aid of the high temperature of the electric arc; that method has been successfully developed, but ares are current wasters, and thus nitric acid and nitrolim industries only prosper in districts of cheap hydro-electric power. The other method, generally identified in recent decades with the name of Ostwald, was the oxidation of ammonia. The principle was well understood, technical application of several processes were spoken of, but particular were not published. In Metall und Erz of January 22 , 1916, however, the director of some sulphuric acid works at Stolberg, near Aachen, in Rhenish Prussia gave some particulars of the method he had introduced in his works. The first point of interest is that the gaseous ammonia is burnt by contact with red-hot platinum, and that the nitric oxide and other nitroge oxides formed are sent directly into the lead chambers, there to effect the oxidation of the sulphur dioxide (from the roasting furnace) to sulphuric acid. Thus nitric acid is, in the new method, not first made and decomposed again into the oxides to oxidize the $\mathrm{SO}$ in the chambers, but the nitrogen oxides resulting from the combustion of ammonia are at once utilized for the oxidation. The particular process applied is that of Frank and Caro. Mr. Schiiphaus, who is an engineer describes first the original plant, and then some improvements which were adopted in his works.

In the original plant the raw material started with was ammonia liquor, which was supplied in cylindrical receivers on trucks. The liquor was run into tanksold boilers-fixed in the ground below the works flooring. From these tanks the liquor was forced by compressed air into mixing tanks in which the liquor and so much milk of lime were mixed under lively stirring that the liquid contained 2 or 3 per cent of ammonia This liquid was then pressed into the top of a colum This liquid was then pressed into the top of a column
apparatus or dephlegmator, consisting of six compartments, while steam at 0.3 atmosphere pressure entere into the bottom compartment. The gaseous ammoni escaped above, while the water flowed back into the dephlegmator. The gas flowed through two coolers in series containing a large number of vertical iron pipes, the ammonia passing through the pipes. The gaseous ammonia then entered two vessels half full of causti soda lye, to be washed and freed of sulphureted hydro gen, phenol and other impurities; a false bottom sep rated the gas current in these vessels into a large number of fine gas jets, to secure intimate contact with the caustic soda. Leaving these washers, the gas was sent into a gas holder of small capacity, 5 cubic meters. The whole arrangements, liquor feed, steam pressure cooling, etc., were so regulated that the liquid should boil only in the lower compartment of the dephlegmator, not in the top compartment, that water vapor should be condensed in the first cooler, but the temperature remain sufficiently high there to facilitate the evapora- interpretati

Our conclusion, therefore, is the opposite of that which Bergson advocates. It is intellect which is molded upon life and which, revealing to us the universal, the one-in-many, will also reveal to us the essential logic of life's self-development in organization. In the stereotyped and narrow character of instinct we shall never find a clue to life's nature. If Bergson's main contention thus appears mistaken, is there no value in his work? To answer this question we should first make certain distinctions and abstractions in relation to his contentions. Let us set aside his false conception of intellect as merely analytic, and of life as purely contingent, and abstract also from his belief that it is life in particular which intellect cannot comprehend. We shall then see that his contention, when separated from all which makes it unique and specific, is reducible to the position that there are some aspects of reality which our understanding cannot truly comprehend. With this statement, in its purely general form, we cordially agree. In so far, also, as Bergson's insistence upon intuition may be taken as meaning that intellect must be supplemented by other forms of consciousness, there again we must agree. We feel that nothing less than man's whole consciousness is needed to comprehend the problems of existence. Nor is this untrue in relation to the specific study of life. We have insisted that intellect is competent to reveal to us life's essential process, the logic which underlies its operations. But there is more in a thing than its essence, and there is more than logic in life. Feeling and emotion and sympathy may all find a place in this study. It is thus that we should understand Bergson's mistaken attempt to replace intellect by its mere opposite. tion of the ammonia, and that the gas holder should serve also as a pressure register to balance fluctuations in the ammonia pressure.

From the gas holder the gaseous ammonia was, and is, sent into the "combustion elements" apparatus, of which three were installed for the lead chambers of works producing 10,000 tons of a sulphuric acid of 60 per cent per year. Ammonia and air are mixed in correct proportions (secured by fans and by diaphragms and valves in the lines) and sent into the mixing chamber of a combustion unit, passing first through several layers of iron wire netting, which is provided to make the mixture uniform; the gases then strike the horizontal net of platinum gauze which acts as catalyst. This gauze is exceedingly fine, almost like a silk texture, and is held on either side by a pair of brass bars, silvered on their surface; the brass bars are connected with the current leads, which introduce currents of 125 or 150 amperes at 20 or 25 volts. At the temperature of the dark-red glow of the platinum (about $700 \mathrm{deg}$. Cent.) the ammonia is completely burnt to nitric oxide and water. The gases pass upward into a pyramidical hood of iron (lined inside with aluminium), and through an aluminium elbow into the pipe (common to the three units) entering the lead chambers. The aluminium lining is required lest iron oxide drop down upon the platinum gauze. The pipes are of iron, the fans of aluminium. The flanges in the ammonia conduits are packed with rubber, or oil and asbestos, or with a material called klingert; to keep the top of the dephlegmator gas-tight, a layer of 5 millimeters thickness of a very stiff paste of minium and oil is applied. To prevent saturation of the water of the gas holder with ammonia, oil is poure on the water; a slight percentage of ammonia in the water is desirable to prevent freezing; the oil also avoids losses of ammonia by evaporation from the annular space between the bell and the body of the gas holder. In the combustion apparatus the space just below the platinum gauze is waterjacketed, lest any ammonia should be decomposed by the heat before being burnt; otherwise nitrogen would escape unoxidized.

So far the original plant. There was trouble with the lime, which clogge the ports in the dephlegmator, and for this and for other reasons liquid ammonia of 25 per cent was substituted as raw material for the crude liquor. The plant was thus much simplified, the mixing tanks and the soda washers, as well as the settling tanks (in which the cooling water was cooled and clarified for re-use), becoming dispensable. The attendance was minimized, moreover, the ammonia feed alone requiring occasional adjustment by the man looking after the lead chamber. The Berlin-Anhaltische Maschinenbau-A.G.-which manufactures and supplies the whole apparatus above described-has recently added a valve which automatically controls the bell of the gas holder, so that there is no need for any attendance at all. The use of liquid ammonia ha another very essential advantage. When the liquor was used, the dephlegmator could deal with 5 cubic meters of liquid per 25 hours, which meant that the 2.5 per cent liquor could yield 125 kilogrammes of 2.5 per cent liquor could yield 125 kilogrammes of
gaseous ammonia per day. By starting with liquid ammonia of 25 per cent the capacity was raised tenfold, to 1,250 kilogrammes. Now that amount of ammonia suffices to keep several lead chamber systems going, and one combustion unit has proved sufficient for producing 10,000 tons per annum of sulphuric acid of 60 per cent.

The nitrogen oxides were first introduced into the connection between the Glover tower and the main chamber, in order to become well mixed with the sulphurous oxides. With this arrangement, however, a long iron pipe ( 9 meters in length) was required for the nitric oxide, and the iron was attacked and stop- pages arose. To avoid this the combustion units are now mounted close to the main lead chamber, and the iron pipe from the units ends in an earthenware pipe which penetrates by about a foot into the chamber, being inclined, so that any condensed liquid will not come in contact with the walls of the chamber. Trouble has occasionally arisen from impurities in the liquid ammonia; although this material is very good on the whole, there is sometimes a little spongy iron oxide or iron hydroxide in it, which clogs the ports in the dephlegmator. In such a case the dephlegmator has to be taken to pieces, which causes an interruption of several hours. But as one dephlegmator is sufficient, such contingencies need not be feared when two such apparatus are installed.

For some reason the works were also disturbed by temporary failures of the electric current. Then the fans would stop, the gases from the lead chamber would rush back and would poison the platinum gauze, which had to be thoroughly cleaned with hot hydrochloric acid to become catalytically effective again. To obviate this disturbance a flap valve has been inserted into the air line; this valve (of thin sheet iron) floats as long as the fan is going and is sending air into the combustion chamber; when the fan stops, the valve closes, but the ammonia feed continues and keeps back the gases from the lead chamber. To meet other failures part of the nitrogen oxides is sent through a small tower apparatus in which sufficient nitric acid is prepared to help the plant over periods of disturbance.

Mr. Schiiphaus mentions several other technical points of interest. As regards the economy of the process, he merely states that the amount of nitrogen wanted in the new process keeps within the limits of the nitrogen consumption on the former nitric acid working. Things may not be altogether satisfactory and as simple as they appear; but it is interesting to have such an account on the working of a new process. We hope to be able to give, later on, further particulars of the results obtained.

\section{Alloys for Thin Ornamental Castings}

THE alloys used in the making of thin ornamental castings for cash registers were described in a paper by R. S. B. Wallace, National Cash Register Company, pre sented to the American Institute of Metals at its meet ing at Cleveland. Two classes of alloys are used, one for bronze finish parts and one for nickel-plated parts. for bronze finish pronze finish, the alloy is:

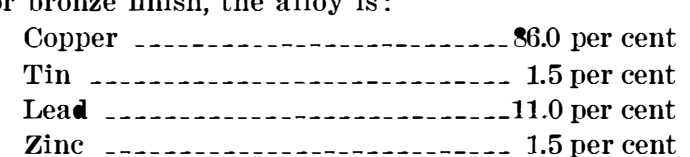

$1 / 20$ oz. of manganese-copper per $1 \mathrm{~b}$ of copper.

For the nicked-plated parts the alloy is:

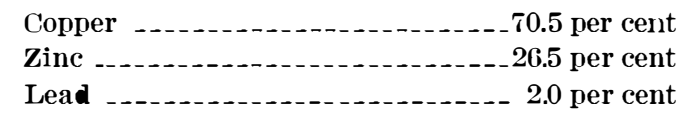

Lead - Tin -

In all mixtures the zinc, tin and lead are made into alloys which reduce the cost of weighing the necessary metals and eliminate the chances of error.

In melting the metal it must at all times be covered with charcoal. After the crucible has been placed in the furnace and the necessary coke around it, a few pounds of gates or scrap metal of the same composition required in the heat are placed in the bottom of the crucible, and the copper is placed across the top of the crucible at the same time. By the time the gates are melted the copper is ready to be placed in the crucible and as the copper melts it falls into the bath of metal made by the melting of the gates. After the metal has become properly melted the necessary alloy is added in proportion to the amount of copper.-The Iron Age. 